\title{
International Winter Wheat Improvement Program: history, activities, impact and future
}

\author{
Alexey MORGOUNOV $(\bowtie)^{1}$, Fatih OZDEMIR ${ }^{2}$, Mesut KESER $^{3}$, Beyhan AKIN $^{1}$, Thomas PAYNE ${ }^{4}$, \\ Hans-Joachim BRAUN ${ }^{4}$ \\ 1 International Maize and Wheat Improvement Center (CIMMYT), Ankara 06511, Turkey \\ 2 Bahri Dagdas International Agricultural Research Institute, Konya 42001, Turkey \\ 3 International Center for Agricultural Research in Dry Areas (ICARDA), Ankara 06511, Turkey \\ 4 International Maize and Wheat Improvement Center (CIMMYT), Texcoco 56100, Mexico
}

\begin{abstract}
International Winter Wheat Improvement Program (IWWIP) was established in 1986 between the Government of Turkey and CIMMYT with three main objectives: (1) develop winter/facultative germplasm for Central and West Asia, (2) facilitate global winter wheat germplasm exchange, and (3) training wheat scientists. ICARDA joined the program in 1991 making it a threeway partnership that continues to work effectively. The germplasm developed by IWWIP as well as the winter wheat cultivars and lines received from global cooperators are assembled into international nurseries. These nurseries are offered annually to public and private entities (IWWIP website) and distributed to more than 100 cooperators in all continents. IWWIP impact has primarily been in new winter wheat cultivars combining broad adaptation, high yield potential, drought tolerance and disease resistance. A total of 93 IWWIP cultivars have been released in 11 countries occupying annually an estimated 2.5-3.0 Mha. IWWIP cooperation with researchers in Turkey, Central and West Asia and several US universities has resulted in a number of publications reviewed in this paper. Important IWWIP impacts include national inventories of wheat landraces in Turkey, Tajikistan and Uzbekistan, their collection, characterization, evaluation and utilization.
\end{abstract}

Keywords biotic and abiotic stresses, breeding, methodology, winter wheat

\section{Role of winter wheat in the global context and production environments}

Wheat is a major food crop globally accounting for $18 \%$ $20 \%$ of all calories consumed, grown on 218 Mha of land

Received March 6, 2019; accepted April 17, 2019

Correspondence: a.morgounov@cgiar.org and producing $771 \mathrm{Mt}$ of grain (FAO website). Two major types of wheat are cultivated: bread wheat (Triticum aestivum subsp. aestivum) and durum wheat (T. turgidum subsp. durum). Each species contains environmentally adapted subtypes; winter wheat adapted to cold temperatures requires vernalization exposure to low temperature in order to initiate floral development, spring wheat requiring no vernalization is grown in milder equatorial regions and at higher latitudes (above $45^{\circ}$ ); and facultative wheat with weak vernalization requirements is grown in areas with mild winters and can be planted both in autumn or early spring. Vernalization allows cereals to survive cold temperatures during winter. China has the largest area sown for wheat production, followed by the USA, India and the Russian Federation. Kazakhstan and Canada, ranking fifth and sixth, produce wheat on about half the area of the top four countries. The major winter wheat production area is located in Central and West Asia (CWA) and occupies an estimated 14 Mha.

The importance of wheat in CWA for food security is extremely high. According to the Food and Agriculture Organization of the United Nations (FAO) data, wheat consumption here is the highest in the world exceeding $200 \mathrm{~kg}$ per person per year. Wheat and wheat products contribute up to $50 \%$ of daily calories consumption especially in rural areas. Cultivated wheat originated in the region and for this reason it plays a very important role in the diversity of the crop and its relatives. The key production figures of the CWA countries from 1996 to 2017 are presented in Table 1 (FAO website). In Georgia and Kyrgyzstan, reduction in area and yield resulted in substantial production decrease in 2013-2017. As a result, these countries now import more than $50 \%$ of their wheat grain needs. In Turkmenistan, reduction in grain yield was compensated for by doubling the area sown to wheat, yet more than $40 \%$ of the country's wheat grain needs are imported. Production in Azerbaijan and Iran is 
Table 1 Key wheat production statistics for countries of Central and West Asia in 1996-2017

\begin{tabular}{|c|c|c|c|c|c|c|c|c|c|c|}
\hline \multirow{2}{*}{ Country } & \multicolumn{3}{|c|}{ Area/Mha } & \multicolumn{3}{|c|}{ Yield $/\left(\mathrm{t} \cdot \mathrm{ha}^{-1}\right)$} & \multicolumn{3}{|c|}{ Production/Mt } & \multirow{2}{*}{$\begin{array}{l}\text { Import or } \\
\text { export*/Mt }\end{array}$} \\
\hline & $1996-2000$ & $2013-2017$ & $\%$ change & $1996-2000$ & $2013-2017$ & $\%$ change & $1996-2000$ & $2013-2017$ & $\%$ change & \\
\hline Afghanistan & 2.08 & 2.35 & +12.7 & 1.13 & 2.05 & +81.5 & 2.36 & 4.81 & +103.6 & -0.26 \\
\hline Armenia & 0.11 & 0.10 & -5.0 & 1.95 & 3.02 & +55.3 & 0.20 & 0.31 & +50.7 & -0.31 \\
\hline Azerbaijan & 0.48 & 0.60 & +25.2 & 1.85 & 2.81 & +51.9 & 0.89 & 1.69 & +90.1 & -1.29 \\
\hline Georgia & 0.12 & 0.04 & -61.6 & 1.46 & 2.11 & +45.1 & 0.17 & 0.10 & -44.3 & -0.55 \\
\hline Iran & 5.73 & 6.16 & +7.5 & 1.71 & 1.95 & +14.5 & 9.75 & 12.00 & +23.0 & -4.21 \\
\hline Kazakhstan & 9.95 & 12.20 & +22.1 & 0.85 & 1.16 & +37.1 & 8.34 & 14.10 & +69.0 & +4.33 \\
\hline Kyrgyzstan & 0.49 & 0.30 & -38.3 & 2.29 & 2.26 & -1.5 & 1.12 & 0.67 & -39.9 & -0.33 \\
\hline Tajikistan & 0.33 & 0.30 & -8.9 & 1.12 & 3.04 & +171.4 & 0.37 & 0.91 & +144.7 & -0.82 \\
\hline Turkey & 9.26 & 7.74 & -16.4 & 2.10 & 2.73 & +30.3 & 19.40 & 21.10 & +8.9 & -4.48 \\
\hline Turkmenistan & 0.58 & 1.39 & +142.0 & 1.92 & 1.00 & -47.8 & 1.12 & 1.36 & +21.5 & -0.61 \\
\hline Uzbekistan & 1.40 & 1.44 & +3.1 & 2.45 & 4.69 & +91.3 & 3.43 & 6.76 & +97.2 & -1.17 \\
\hline
\end{tabular}

Note: *, average annual wheat import $(-)$ or export $(+)$ in $2013-2016$.

characterized by modest increases both in area and yield, yet still requiring more than $40 \%$ grain importation. Turkey imports more than $4 \mathrm{Mt}$ per year but essentially all of this wheat is re-exported as flour. Afghanistan, Tajikistan and Uzbekistan have doubled the production due to very high increase in grain yield but are still dependent on grain imports. Kazakhstan is the only grain exporting country in the region, with low yields sown on vast areas. Clearly, despite spectacular yield and production gains in some of the countries, food security and dependence on imported wheat remains an important challenge.

The concept of wheat mega-environments (MEs), to describe major wheat production environments, was formulated by Rajaram et al. ${ }^{[1]}$. An ME is defined as a broad, not necessarily continuous, area with similar biotic and abiotic stresses, cropping system requirements and consumer preferences. Six facultative and winter wheat production MEs have been elaborated by Braun et al. ${ }^{[2]}$.

- ME 7 (9 Mha) represents moderately cold, irrigated production areas in China and CWA. The main abiotic stress is high temperature at grain fill and maturity. The prevailing diseases are yellow, leaf and stem rusts.

- ME 8 (0.7 Mha) is high rainfall facultative wheat in the mountains of Turkey and South America.

- ME 9 (6.8 Mha) is dryland ( $<400 \mathrm{~mm})$ facultative wheat subjected to moisture and heat stress with less effect of diseases.

- ME 10 (6.2 Mha) represents areas sown to winter wheat grown under irrigated, severe cold. Beijing (China) is typical of this ME.

- ME 11 (0.9 Mha) represents irrigated, high rainfall winter wheat areas with moderate to severe cold. Temuco Chile and Lovrin Romania are typical sites of this ME.

- ME 12 (7.9 Mha) represents dry low rainfall winter wheat areas. Ankara Turkey is typical of the ME.

However, annual fluctuations in weather and disease intensity can affect spatial MEs conditions, yield potential for irrigated and drought prone environments, coupled with heat tolerance during the grain formation stages, and frost and winter hardiness. Lack of adequate resistance to yellow and leaf rust remains a highly important constraint.

\section{International Winter Wheat Improvement Program (IWWIP) history}

The key development for global wheat production was the Green Revolution. The success of high-yielding semi-dwarf spring wheat cultivars from Mexico in the 1960s resulted from worldwide adoption and substantial yield increases. CIMMYT was established in 1966 and continued the spring wheat shuttle breeding program in Mexico, developing broadly adapted, high-yielding disease resistant germplasm, which was distributed through the International Wheat Improvement Network nurseries. In the late 1970s, CIMMYT established regional outreach offices in the key wheat producing countries throughout the developing world to promote new spring wheat cultivars, and to improve local wheat production agronomy.

In 1986, the Government of Turkey and CIMMYT established IWWIP aiming to develop winter wheat germplasm suitable for the CWA, facilitating global germplasm exchange and training wheat breeders and researchers. In 1991, ICARDA joined IWWIP making it a three-partnership program that is still continuing. The IWWIP nursery Facultative and Winter Wheat Observation Nursery (FAWWON) was established in 1991 and continues to distribute diverse germplasm to wheat 
improvement programs worldwide.

IWWIPs at the University of Nebraska-Lincoln (UNL), the University of California-Davis (UCD) and Oregon State University (OSU) preceded the IWWIP. The UNL and United States Department of Agriculture (USDA) started the global distribution of the International Winter Wheat Performance Nursery in $1968^{[3]}$. The nursery consisted of 30 entries annually and was grown in yield trials with replicated entries. The germplasm for the nursery was provided to 29 countries and represented a wide diversity of improved materials. Its main objective was the identification of broadly adapted winter wheat to be used as parent material. The second initiative, the $\mathrm{UCD} / \mathrm{OSU}$ winter $\mathrm{x}$ spring program, started in the late 1960s in collaboration with the Rockefeller Foundation and CIMMYT. The objective was to use spring wheat to develop broadly adapted, disease resistant winter cultivars for the major winter and facultative wheat producing areas of the world. IWWIP established in 1986, eventually replaced both the UNL-USDA and OSU programs, however, it inherited the breeding philosophy, technical approaches and the wide network of winter wheat collaborators.

Since the early 2000s, Turkey, CIMMYT and ICARDA have strengthened their IWWIP partnership focusing on germplasm development, facilitation of global germplasm exchange, conducting priority research and contributing to capacity building through targeted training. The majority of the breeding activities have been conducted in collaboration with public agricultural research institutes.

\section{Current IWWIP breeding system}

The IWWIP breeding strategy is based on the need to develop modern competitive winter and facultative bread wheat germplasm, which can complement public and private breeding efforts. Over the past 10 years, IWWIP has also conducted pre-breeding utilizing regional wheat landraces and primary synthetic hexaploids to diversify its germplasm genetic diversity and offer new diversity to its partners. The IWWIP breeding system is defined by regional priority traits and the opportunity to conduct evaluation in Turkey and throughout the region. IWWIP has also assisted its partners to clarify their priority traits, environments and germplasm. Yield potential and stability remain the key breeding objective for all environments. Water use efficiency is an increasingly important priority for areas where supplementary irrigation is applied once or twice during the growing season. Drought tolerance remains a key trait for rainfed semiarid areas across the region. This trait has now been combined with responsiveness to moisture availability benefitting farmers in years with good precipitation or when they are able to irrigate. The order of priority for pathogen resistance is yellow rust, leaf rust, stem rust, soilborne pathogens (nematodes and dryland root rot fungi), common bunt and septoria. Bread-making quality has increased in priority recently.

The IWWIP breeding framework uses the diversity of the wheat production environments in Turkey for evaluation and testing. The wheat breeding sites and breeding targets are in:

- Konya at the Bahri Dagdas International Agricultural Research Institute, the formal IWWIP counterpart in Turkey and key breeding and nursery processing site (irrigated and dryland yield trials, seed health facility, preparation and distribution of international nurseries).

- Edirne at the Thrace Agricultural Research Institute (high yield potential, cold, leaf and yellow rust).

- Eskisehir at the Transitional Zone Agricultural Research Institute (irrigated and dryland yield trials, soilborne pathogens and common bunt evaluation).

- Ankara at the Central Field Crop Research Institute (dryland yield trials, yellow, leaf and stem rust evaluation under artificial inoculation in the field and greenhouse).

- Erzurum at the East Anatolia Agricultural Research Institute (irrigated and dryland yield trials, severe cold, yellow and stem rust).

- Izmir at the Aegean Agricultural Research Institute, a key site conducting all IWWIP crosses, evaluation of introductions and rust resistance using Turkey-ICARDA Rust Center, and the coastal Mediterranean (Adana) and Black Sea (Sakarya, Samsun) regions at sites mostly used for evaluation of disease resistance, primarily rusts and septoria.

Annually, 850-1000 crosses are made, including winter $\mathrm{x}$ winter $(30 \%)$, winter $\mathrm{x}$ spring $(30 \%)$, back or top crosses $(30 \%)$ and pre-breeding or research crosses $(10 \%)$. The $\mathrm{F}_{2}$ segregating populations are grown space planted in Edirne and exposed to leaf and yellow rust infection. Selected plants are bulked and $\mathrm{F}_{3}$ crosses destined for irrigated environments are planted in Diyarbakir for individual plant/spikes selection. The selected spikes are planted as $\mathrm{F}_{4}$ head-rows in Eskisehir (on average 25000 per year), selected and bulked for $\mathrm{F}_{5}$ preliminary yield trials in Eskisehir and other locations. The $\mathrm{F}_{6}$ yield trials and $\mathrm{F}_{7}$ advanced yield trials are planted at an increasing number of sites with two and three replicates, respectively. The germplasm destined for semiarid conditions starting from $\mathrm{F}_{3}$ is exposed to dryland moisture stressed conditions in Konya or Ankara and the individual spike selection is conducted in $\mathrm{F}_{5}$. Additional spike selection is done in advanced yield trial level for breeding lines purification before multiplication for international distribution. This established winter wheat breeding system takes 9-10 years from the cross to international distribution. An alternative faster system was started in 2018 using a speed breeding facility in Izmir allowing two to three generations per year. In this case the progeny of superior $\mathrm{F}_{2}$ plants are fasttracked to $\mathrm{F}_{4}-\mathrm{F}_{5}$ head-rows within one calendar year. Additional breeding activities were conducted at ICARDA 
Headquarter in Aleppo, Syria and the material was incorporated with the germplasm developed in Turkey until the program was moved from Syria to Lebanon due to turmoil. Currently, the material developed by ICARDA based breeders in Terbol, Lebanon is sent to Turkey for inclusion to IWWIP international nurseries.

Until recently, the IWWIP remained largely a conventional breeding program. However, as the knowledge of molecular markers accumulated and the effects of the markers on agronomic traits were demonstrated, new genomic tools were gradually incorporated into the IWWIP breeding scheme. In 2017, IWWIP breeders analyzed functional and random KASP markers on a large germplasm set (exceeding 1500) comprising its own material and the germplasm from cooperators in the region. The frequency of different markers in winter wheat germplasm was analyzed and related to agronomic performance. In 2018, all FAWWON candidates were genotyped for functional KASP markers. The effects of the markers on priority traits are now being analyzed and validated. Normalized difference vegetation index (NDVI) measurements taken with a hand-held crop sensor, have been routinely used for germplasm evaluation especially at a preliminary yield testing stage. The data provides useful additional information for selection. IWWIP organized phenotyping workshop in 2018 in Konya laying a foundation for wider application of modern phenotyping tools. Breeding for superior bread-making quality is based on selection of parents using high- and low-molecular glutenins and germplasm screening for dough physical properties in the $\mathrm{F}_{5}-\mathrm{F}_{6}$ generations.

From the time of its establishment, IWWIP has maintained close relation with the key winter wheat breeding programs in the region and globally. The main cooperation area is germplasm exchange. Many breeding programs share their new cultivars and advanced breeding lines with IWWIP. Annually, IWWIP receives 250-350 new genotypes from the main winter wheat production areas. The long-term cooperators willingly sharing the germplasm are in Azerbaijan (Azeri Farming Research Institute), Bulgaria (Dobrudzha Agricultural Institute), Hungary (Martonvasar Agricultural Research Institute), Iran (Seed and Plant Improvement Institute, Dryland Agricultural Research Institute), Kazakhstan (Kazakh Farming Research Institute), Romania (Fundulea Agricultural Research Institute), Russia (Krasnodar Agricultural Research Institute), Switzerland (Agroecology Research Station), Tajikistan (Tajik Farming Research Institute), Ukraine (Kharkov Crop Production Research Institute), and US universities in Colorado, Kansas, Nebraska, Oklahoma, Oregon, Texas and Washington. This material goes through quarantine inspection in Turkey, is planted for primary evaluation on small plots in locations highly conducive to the key diseases. If the germplasm possesses disease resistance and general adaptation traits, it is multiplied and yield-tested during a second year. Based on the yield trial performance, the germplasm is included into FAWWON and the superior lines into the International Winter Wheat Yield Trials (IWWYT). All materials are distributed under the terms and conditions of the Standard Material Transfer Agreement of the ITPGRFA. Multilocational data from international nurseries are annually integrated and distributed to all cooperators. The breeding and research programs, which share the material, benefit greatly through access to the data on their cultivars and lines collected in diverse regions and environments.

IWWIP assembles and distributes two types of international nurseries. The objective of FAWWON is to deliver relatively large number of diverse genotypes with 10-15 g of seeds per entry. FAWWON for irrigated environments comprises short stature high-yielding germplasm developed by IWWIP and contributed by the cooperators. The nursery normally comprises 150 entries with $60 \%-70 \%$ originating from IWWIP. FAWWON for semiarid environments includes around 100 entries with resistance to moisture stress as demonstrated in Turkey. The germplasm in this nursery may have variable height and some tall lines may also be included. IWWIP-originated germplasm comprises up to $80 \%-90 \%$ of this nursery. The second type of activity at the international nurseries, replicated yield trials called IWWYT, has only 35-40 entries with two replicates. The amount of seeds provided is sufficient for machine planted plots. Elite germplasm proven to perform well in FAWWON is selected for IWWYT. The objective of this nursery is to identify broadly adapted high-yielding germplasm, which can be potentially used as cultivars and parent material. The characteristics of the germplasm introduced into IWWYT is very similar to that in FAWWON. Special nurseries have been assembled that respond to cooperators needs, including a stem rust resistance nursery, yellow rust and common bunt resistance nursery, and soilborne pathogen resistance nursery. Expression of a specific trait is important for selection of germplasm for special nurseries as well as information on genetic background of resistance.

IWWIP cooperators can request the nurseries through the IWWIP website. Annually, more than 250 nurseries are distributed to more than 80 cooperators in $35-45$ countries. Data collection and nursery report preparation is very important in order to provide the information to cooperators. Once the wheat season is finished, data on all nurseries are collected, assembled into a simple spreadsheet and distributed to cooperators in early January.

\section{Research highlights}

IWWIP research addresses priority topics to understand the underlying environmental and genetic interactions and develop more efficient breeding systems. Since wheat rusts are the major diseases in the region and the highest priority for IWWIP breeding, several studies have been devoted to 
rust resistance. Data from international nurseries from 1969 to 2010 from 51 countries were analyzed for winter wheat $\mathrm{cv}$. Bezostaya 1 disease incidence and severity ${ }^{[4]}$. The incidence of leaf rust and stripe rust was stable over time with marked increases in severity in 2001-2010 especially in Europe and CWA. Substantial global reductions in stem rust occurrence were recorded and attributed primarily to use of resistance genes although the recent emergence of race $U g 99$ makes wheat more vulnerable. The durable resistance of cv. Bezostaya 1 to all four diseases was demonstrated in the study using comparisons of disease severities of Bezostaya 1 and the most susceptible entries. The $\operatorname{Lr} 34 / \mathrm{Yr} 18 / \mathrm{Pm} 38$ pleiotropic set possessed by Bezostaya 1 is an important target for selection.

Cooperative studies with Washington State University and USDA examined genetics of adult plant resistance to yellow rust in 100 IWWIP genotypes ${ }^{[5]}$. Gene $\operatorname{Yr} 18$ contributing to adult plant resistance was found in $44 \%$ of the entries studied. The other genes present were $Y r 9$ and $\mathrm{Yr} 17$ but $\mathrm{Yr} 5, \mathrm{Yr} 10$ and $\mathrm{Yr} 15$ were not identified. The results suggest that resistance in most of the germplasm is controlled by adult plant resistant genes. The study of 70 IWWIP lines for leaf rust resistance identified the following most common genes present: $\operatorname{Lrl}, \operatorname{Lr} 3 a, \operatorname{Lr} 10$, $\operatorname{Lr} 12, \operatorname{Lr} 17, \operatorname{Lr} 23$ and $\operatorname{Lr} 34^{[6]}$. Adult plant resistance to leaf rust was common among the material tested.

The threat of stem rust $U g 99$ prompted research on the genetics of winter wheat resistance to this pathogen. Collaborative research with Cornell University on haplotype diversity among a diverse set demonstrated that IWWIP winter wheat was more similar to US winter wheat than to CIMMYT spring wheat. $\mathrm{Sr} 2$ was much less common than in spring wheat but the frequency of $1 \mathrm{~A} .1 \mathrm{R}$ translocation was much higher ${ }^{[7]}$. The follow up study of genome wide association mapping involved 232 IWWIP genotypes tested in Kenya and Turkey ${ }^{[8]}$. Twelve loci associated with $U g 99$ resistance were identified including markers linked to known genes $\mathrm{Sr} 2$ and Lr34. Other markers were located in the chromosome regions where no $\mathrm{Sr}$ genes have been previously reported, including one each on chromosomes $1 \mathrm{~A}, 2 \mathrm{~B}, 4 \mathrm{~A}$ and $7 \mathrm{~B}$, two on chromosomes $5 \mathrm{~B}$ and four on chromosome $6 \mathrm{~B}$. This study established the basis for development and application of markers for utilization in breeding.

Increasing application of fungicides on wheat in the region and globally inspired experiments in Turkey and Kazakhstan to evaluate response to fungicide protection in winter wheat germplasm with variable degrees of resistance ${ }^{[9]}$. The yield loss of genotypes susceptible to leaf rust varied from $30 \%$ to $60 \%$ depending on the environment and severity of infection. Genotypes completely or moderately resistant to leaf rust also responded positively to fungicide protection, with average yield increasing by $10 \%-30 \%$. The main character affected by fungicide was 1000 -kernel weight. There was stable expression of the magnitude of yield gain in resistant genotypes in different seasons, confirming genetic variation for this trait. The magnitude of yield gain by resistant germplasm justifies its capture in breeding programs to develop cultivars resistant to diseases and with greater benefits from fungicide protection.

IWWIP made a focused effort to analyze the climate change in central Asia, eastern Europe and Great Plains of the USA from 1961 to $2009^{[10]}$. The key weather parameters (monthly minimum and maximum temperature, and precipitation) were obtained for 35 winter wheat breeding sites. Autumn and winter warming happened gradually, over a long period of time, but mostly before 1991. Climate changes after 1991 were mainly expressed through higher temperatures in spring and early summer. Breeding sites in the USA seemed to be least subject to climate change. There were no significant linear trends in yearly, seasonal or monthly precipitation. Changing climates expressed through rising temperatures during critical stages of winter wheat development have already negatively affected yield gains in several countries, especially in Eastern Europe. Rising temperatures in spring are of particular concern since their effect on yield is negative. They certainly accelerate wheat development and shift heading to earlier dates. Rising temperatures in June are detrimental for grain development and filling and heat tolerance warrants high priority in breeding programs. Following up this analysis, a drought platform was established in Turkey side by side with a comparison of germplasm under drip-irrigation and rainfed conditions. Different physiologic tools were tested to assist in identification of drought resistant material ${ }^{[11]}$. NDVI readings and digital photos demonstrated similar capacity for predicting yield under moisture stress.

IWWIP conducted two genetic gain studies in Turkey to document the progress in grain yield and associated traits. For irrigated wheat, 14 cultivars released in 1963-2004 were tested in 16 environments from 2008 to $2012^{[12]}$. The highest yields were achieved by the recent cultivars, Kinaci-97 $\left(5.48 \mathrm{t} \cdot \mathrm{ha}^{-1}\right)$, Cetinel-2000 $\left(5.39 \mathrm{t} \cdot \mathrm{ha}^{-1}\right)$, Alpu$2001\left(5.44 \mathrm{t} \cdot \mathrm{ha}^{-1}\right)$ and some others. The progress reached in grain yield in 20 years was $58 \mathrm{~kg} \cdot \mathrm{ha}^{-1}(1.37 \%)$ per year. This gain was mainly achieved through shorter plant height and increased harvest index. There was no clear tendency for changes in specific yield components, demonstrating that new high-yielding cultivars may have different ways to reach their yield potentials. The yield gains were accompanied by improved stripe rust and leaf rust resistances primarily based on adult plant resistance genes. The paper also contains a detailed map of wheat production zones in Turkey with the rainfall and basic production statistics. The second study evaluated genetic gains using 22 winter/facultative cultivars released for rainfed dry conditions between 1931 and $2006^{[13]}$. The study was conducted at three locations in Turkey during 2008-2012, with 21 test sites. Mean yield across all 
locations was $3.34 \mathrm{t} \cdot \mathrm{ha}^{-1}$ but varied from 1.11 to $6.02 \mathrm{t} \cdot \mathrm{ha}^{-1}$ and was highly affected by moisture stress. Annual genetic gain was $0.50 \%$ compared to landrace Ak-702, or $0.30 \%$ compared to the first modern landmark cultivar. Modern cultivars had both improved yield potential and tolerance to moisture stress. The number of spikes per unit area decreased by $10 \%$ over the study period, but grains per spike and 1000-kernel weight increased by $10 \%$. The findings from these two studies have been used in the IWWIP breeding framework. Several cultivars included in both studies originated from IWWIP and the results demonstrated their impact in farmer's fields.

CIMMYT Soil Borne Pathogen (SBP) group has been based in Turkey since 2001. Cereal cyst nematodes (CCN) causes significant economic yield losses alone or in combination with other biotic and abiotic factors in Turkey and the region ${ }^{[14]}$. $\mathrm{CCN}$ species, Heterodera avenae, $H$. filipjevi, and $H$. latipons are considered the most economically important in wheat. In 2012-2014, 719 wheat lines from FAWWON, representing a broad geographical spectrum of breeding lines and cultivars from Europe, Central Asia and IWWIP were screened against $H$. filipjevi under controlled conditions ${ }^{[15]}$. The results indicated that 114 and 90 genotypes were ranked resistant and moderately resistant, representing $15.8 \%$ and $12.5 \%$ of the screened genotypes, respectively. The frequency of resistant genotypes observed in the germplasm varied significantly between the entries from different countries and was the highest for genotypes that originated from Bulgaria (59.3\%). A subset from this study with 181 genotypes was used for genome-wide association mapping of CCN resistance ${ }^{[16]}$. Eleven novel QTLs on chromosomes 1A, 2A, 2B, 3A, 3B, 4A, 5B, and 7B were identified. All significant markers explained $43 \%$ of total genetic variation. Seven SNP markers on chromosome $1 \mathrm{AL}, 2 \mathrm{AS}, 2 \mathrm{BL}, 3 \mathrm{AL}$ and $4 \mathrm{AL}$ were linked to putative genes involved in biotic stress and plant pathogen interaction. Three markers on 3BL and 7BL were linked to putative genes involved in abiotic stress. This study laid a foundation for development and utilization of molecular markers to be used in breeding.

The SBP group also works on dryland crown rot (Fusarium culmorum) resistance and has screened a large number of genotypes. In the recent study 141 genotypes and breeding lines from 19 different countries, provided by IWWIP were screened for resistance to a local isolate of F. culmorum under three different environmental conditions (growth room, greenhouse and field) in Turkey in $2012^{[17]}$. The best genotypes in terms of resistance were then rescreened in 2013 for resistance validation. Of 141 wheat genotypes, $17(12 \%)$ ranked as moderately resistant at seedling and/or adult growth stage. The genotypes from Mexico seemed to have adult plant resistance rather than seedling resistance which was higher in the USA genotypes. CIMMYT-Turkey SBP group routinely evaluates hundreds of genotypes provided by IWWIP. The best resistant material is used in IWWIP crosses and is distributed to breeding and research programs through IWWIP international nurseries.

In collaboration with Oregon State University, IWWIP operated Winter Wheat Eastern European Regional Yield Trial (WWEERYT) in 1998-2005 using elite lines and cultivars from IWWIP, Eastern Europe (EE), the USA and CWA. A study by Sharma et al. ${ }^{18]}$ analyzed data to identify superior genotypes and key locations that could be useful for future international collaboration on winter wheat. Grain yield and agronomic traits of 422 elite breeding lines and new cultivars from 17 countries were evaluated across 39 locations. Eleven superior genotypes were identified for both EE and CWA. The most representative and discriminating sites for grain yield were Konya and Eskisehir, Turkey (overall), Edirne, Turkey (CWA) and Dobrich, Bulgaria (EE). These results proved that IWWIP key breeding sites in Turkey are effective in identifying high-yielding material. The follow up study in cooperation with Colorado State University analyzed population structure and genetic diversity of 283 genotypes from WWEERYT ${ }^{[19]}$. The collection was genotyped with single-nucleotide polymorphism (SNP) markers obtained via genotyping-by-sequencing. Population structure comprised seven subpopulations with the breeding program of origin closely related to subpopulation assignment. The closest relation was between a population of predominately IWWIP genotypes and genotypes from the USA, indicating a close relationship between these two groups. The results of the study fostered the utilization of WWEERYT germplasm.

Colorado State University also evaluated winter injury of 287 genotypes from FAWWON in 6 field environments in Colorado over 3 years $(2014-2016)^{[20]}$. Entries were genotyped using SNPs obtained by genotyping-by-sequencing and at known vernalization (Vrn-Al, Vrn-B1, and Vrn$D 1)$ and photoperiod (Ppd-Bl and $P p d-D 1)$ loci. Winter injury was observed and visually scored in five of the six environments. Mean genomic selection prediction accuracies across the five environments, obtained through ridge regression best linear unbiased prediction (RR-BLUP) using 23269 SNPs alone as random effects, ranged from 0.26 to 0.74 . Incorporation of alleles at $V r n-A 1, V r n-B 1$ and $V r n-D 1$ loci as fixed effects in the genomic selection models together with GBS markers as random effects provided the highest prediction accuracy ranging from 0.34 to 0.78 across the five environments. Genomic selection models, that incorporate both major and minor genetic factors that influence low-temperature tolerance, improved the model predictions for identifying genotypes that are best adapted to regions where cold winter temperatures are an important production constraint.

Overall, research conducted by IWWIP always targets important priority topics to improve breeding efficiency and germplasm utilization. Many studies are conducted in 
collaboration with advanced research institutions demonstrating IWWIP integration into global wheat research community.

\section{Impact}

The major impact of IWWIP is in the development of winter wheat germplasm which can be directly used in CWA as new cultivars for production by farmers. There are several approaches to measure impact. A formal impact study was undertaken in Turkey by Mazid et al. ${ }^{[21]}$ to evaluate the adoption of five new winter and spring wheat cultivars developed and released by the Turkish national breeding program and through international collaboration. The study results were based on a survey of 781 households selected randomly in the Adana, Ankara, Diyarbakir, Edirne and Konya Provinces of Turkey. The five new wheat cultivars were compared to old improved cultivars released before 1995 that are also still grown by farmers. Adopters of the new cultivars had higher percapita income than non-adopters as compared to the same group using old cultivars. Farmers' knowledge and perception of certain cultivar characteristics and unavailability of adequate and timely seed are the main challenges for wider adoption.

IWWIP conducted three surveys (2007, 2012 and 2015) with its global cooperators to evaluate the breeding and pre-breeding priorities as well as to obtain feedback on the germplasm and services provided. In 2012, 49 programs participated including 19 from CWA, 22 from Europe and eight from North America. Table 2 summarizes the responses to the questions on the usefulness and adoption of IWWIP germplasm. More than $80 \%$ of the respondents classified IWWIP germplasm as useful or very useful with only three programs suggesting limited, if any, use of germplasm from IWWIP. However, almost $50 \%$ of all the breeding programs participating in the survey normally select less than $10 \%$ of the lines in international nurseries. This demonstrates the overall satisfaction of the breeders with the fact that they receive the germplasm, but also indicates there is potential for the proportion of the IWWIP germplasm to increase in half of the programs. The germplasm utilization varies, depending on the region. In the IWWIP immediate target region of CWA, the germplasm is used primarily for direct selection of lines with subsequent testing in the breeding program and development of new cultivars. Some programs also make crosses to IWWIP germplasm. In Europe, the germplasm is mainly used for crosses with $20 \%$ of the programs selecting the lines directly for trials. In America, no germplasm is used for trials but it is used for crosses.

The performance of IWWIP international nursery, FAWWON, and especially replicated trials, IWWYT, provides solid evidence for IWWIP germplasm performance in the region and globally. IWWIP germplasm is competitive, considering both grain yield across multilocational environments and resistance to priority diseases. Superior performance of IWWIP germplasm in CWA was demonstrated by Sharma et al. ${ }^{[22]}$. They analyzed the irrigated trials involving 38 genotypes in 2010 at several sites in Azerbaijan, Uzbekistan, Tajikistan, Iran and Turkey. Based on 2010 data, a set of 16 genotypes combining high yield and resistance to yellow rust was selected and evaluated in 2011. Nine were consistently resistant to yellow rust in both years across all sites. Several lines showed high grain yields and superior agronomic performance across four sites in Uzbekistan and one site in Tajikistan. Two IWWIP-originated genotypes included in the study were released in Uzbekistan and Tajikistan. The study by Tadesse et al. ${ }^{[23]}$ was conducted in order to determine the rate of breeding

Table 2 Results of 2012 IWWIP survey of collaborating programs

\begin{tabular}{|c|c|c|c|c|c|c|}
\hline \multirow{3}{*}{ Region } & \multicolumn{6}{|c|}{ Number and proportion of the breeding programs considering IWWIP germplasm as } \\
\hline & \multicolumn{2}{|c|}{ Not useful } & \multicolumn{2}{|c|}{ Useful } & \multicolumn{2}{|c|}{ Very useful } \\
\hline & Number & $\%$ & Number & $\%$ & Number & $\%$ \\
\hline Central and West Asia & 1 & 5 & 8 & 42 & 8 & 42 \\
\hline Europe & 2 & 9 & 16 & 73 & 2 & 9 \\
\hline America & 0 & 0 & 7 & 87 & 1 & 13 \\
\hline All & 3 & 6 & 31 & 63 & 11 & 22 \\
\hline \multirow{3}{*}{ Region } & \multicolumn{6}{|c|}{ Number and proportion of the breeding programs selecting the following $\%$ of IWWIP germplasm from international nurseries } \\
\hline & \multicolumn{2}{|c|}{$<10 \%$} & \multicolumn{2}{|c|}{$10 \%-30 \%$} & \multicolumn{2}{|c|}{$>30 \%$} \\
\hline & Number & $\%$ & Number & $\%$ & Number & $\%$ \\
\hline Central and West Asia & 4 & 21 & 13 & 68 & 1 & 5 \\
\hline Europe & 13 & 59 & 6 & 27 & 1 & 5 \\
\hline America & 7 & 87 & 1 & 13 & 0 & 0 \\
\hline All & 24 & 49 & 20 & 41 & 2 & 4 \\
\hline
\end{tabular}


progress for yield and related traits at IWWIP using IWWYT data from 1997 to 2010 in irrigated environments across different countries. The relative grain yield of the best line expressed as a proportion of the best check (Kinaci-97), long-term check (Bezostaya 1) and trial mean increased at a rate of $0.6 \%, 1.6 \%$ and $0.2 \%$ per year. Regression analysis indicated that the trial mean has increased at a rate of $91.9 \mathrm{~kg} \cdot \mathrm{ha}^{-1}$ per year $(P=0.007)$. The net realized gain for the best line in trial was $66.2 \pm 19.7 \mathrm{~kg} \cdot \mathrm{ha}^{-1}$ per year $(P=0.01)$. The percent of sites where the best line exceeds the local check in grain yield ranged from $50 \%$ to $87 \%$ across trials. Both studies confirmed competitive performance of IWWIP germplasm and its practical use as cultivars.

The ultimate measure of IWWIP impact is the number of wheat cultivars released in the target region and the respective area covered. By February 2019, 93 cultivars originating from IWWIP have been released in 11 countries (Table 3), with an estimated area of 2.5-3.0 Mha. The releases accelerated in the last three years with 25 new cultivars registered. The impact of IWWIPoriginated cultivars is the highest in the poorer countries, like Afghanistan, Armenia, Kyrgyzstan, Tajikistan, Turkmenistan and Uzbekistan, where the national agricultural research and development system is constrained by economic or civil issues. Depending on the country, the share of IWWIP-originated cultivars grown by farmers varies from $30 \%$ to $100 \%$. Medium income countries like Azerbaijan and Iran also benefit greatly from the varietal diversity offered by IWWIP material. Turkey, as a host country, released the greatest number of IWWIP-originated cultivars, which are produced across all production zones. Many breeding programs in the region depend greatly on wheat germplasm from IWWIP, which represents an alternative to foreign or private company cultivars. The release and promotion of new cultivars is greatly facilitated by the CIMMYT and ICARDA colleagues based in Afghanistan, Iran and Uzbekistan. The full list of IWWIP-originated cultivars is presented in Supplementary Table S1. IWWIP germplasm is widely used in crossing programs and research especially in Europe and North America.

IWWIP impact is not limited to the development of new germplasm used by the breeding programs and farmers. There are several important areas where the program has made a profound impact on wheat research and development directly or indirectly improving the livelihoods of people. In the 1990s, nationwide efforts in Turkey to survey wheat production constraints resulted in identification of $\mathrm{Zn}$ deficiency as a main soil related stress ${ }^{[24]}$. Zn deficiency not only affects wheat production but also results in low $\mathrm{Zn}$ concentration in grain impacting the nutrition of a large population. Subsequently, integrated efforts were undertaken to correct the deficiency through application of $\mathrm{Zn}$ fertilizer as an additive to phosphorus fertilizers. Wheat genotypes were found to differ in the way they extract $\mathrm{Zn}$ from soil and assimilate it in grain. Wheat cultivars with efficient $\mathrm{Zn}$ translocation to grain $(15 \%-25 \%$ higher) were identified, promoted to the farmers and used in breeding. A whole new area of wheat biofortification began in the early 2000s and led to improvement in wheat production and grain nutritional quality in Turkey and neighboring countries. This outstanding work was possible through effective collaboration between Çukurova University (later Sabanci University) and CIMMYT-Turkey. This successful Zn story has been recently described in a review by Cakmak and Kutman ${ }^{[25]}$.

IWWIP initiated and conducted a national inventory of wheat landraces in Turkey in 2009-2014 ${ }^{[26]}$. More than 60 of the 81 provinces in Turkey were visited by

Table 3 The number of cultivars released in Central and West Asia originating from IWWIP

\begin{tabular}{|c|c|c|c|c|c|c|c|}
\hline \multirow{2}{*}{ Country } & \multicolumn{7}{|c|}{ Number of released cultivars } \\
\hline & Pre-1995 & $1996-2000$ & 2001-2005 & $2006-2010$ & $2011-2015$ & $2016+$ & Total \\
\hline Afghanistan & 1 & 2 & 1 & 0 & 1 & 1 & 6 \\
\hline Armenia & 0 & 0 & 0 & 4 & $?$ & $?$ & 4 \\
\hline Azerbaijan & 0 & 0 & 0 & 1 & 2 & 2 & 5 \\
\hline Georgia & 0 & 0 & 1 & 2 & 2 & 2 & 7 \\
\hline Iran & 0 & 1 & 1 & 0 & 3 & 1 & 7 \\
\hline Kazakhstan & 0 & 0 & 0 & 1 & 1 & 0 & 2 \\
\hline Kyrgyzstan & 0 & 0 & 4 & 2 & 3 & 2 & 9 \\
\hline Tajikistan & 0 & 0 & 0 & 3 & 3 & 4 & 10 \\
\hline Turkey & 2 & 6 & 13 & 4 & 3 & 7 & 35 \\
\hline Turkmenistan & 0 & 0 & 1 & 0 & 0 & 2 & 3 \\
\hline Uzbekistan & 0 & 0 & 1 & 0 & 0 & 4 & 5 \\
\hline Total & 3 & 9 & 22 & 17 & 17 & 25 & 93 \\
\hline
\end{tabular}

Note: There is no information for cultivars released in Armenia since 2011. 
survey and collection teams, and wheat landraces were identified and collected from more than 1500 farms. Characterization of the collection identified very wide diversity of the landraces not only in bread and durum wheat but also included rare species like Triticum monococcum, T. turgidum subsp. dicoccum, T. turgidum subsp. polonicum and T. turgidum subsp. turgidum ${ }^{[27]}$. Agronomic evaluation of wheat landraces identified a number of lines with good drought tolerance, disease resistance and grain quality. A set of 170 selections from the landraces was included in a genome-wide association gene mapping study based on phenotypic data from three sites in 2 years ${ }^{[28]}$. Novel genes contributing to grain yield under moisture stress and other agronomic traits were identified. Since 2014 the landraces were involved in targeted crossing by IWWIP to improve both modern wheat type by introduction of drought tolerance as well as landraces types by introduction of disease resistance. The lines originating from these crosses are now entering the yield test stage. The work on wheat landraces was so successful that the International Treaty on Plant Genetic Resources awarded CIMMYT-Turkey a regional project (Afghanistan, Iran and Turkey) to utilize the landraces in breeding and to expand on-farm wheat diversity by promotion of wheat landrace cultivation in the areas they have been grown. With FAO support, similar inventories of wheat landraces were made in Tajikistan ${ }^{[29]}$ and Uzbekistan ${ }^{[30]}$.

Spring wheat synthetics developed at CIMMYT by crossing durum wheat (AB genomes) and Aegilops tauschii (D genome) proved to be an important genetic resource for a number of traits. The work on winter synthetics started in 2004 when winter durum wheat from Ukraine and Romania was crossed with the collection of A. tauschii from the Caspian Sea basin. The segregating populations from these crosses were sent to Turkey and continuously subjected to pedigree selection under drought stress and disease pressure. The resulting synthetics combined high grain yield under moisture stress with resistance to rust, common bunt, soil-borne pathogens and insect pests ${ }^{[31]}$. A set of 130 winter synthetics was selected for cooperative $\mathrm{PhD}$ study with the University of Nebraska-Lincoln. The synthetics were phenotyped in Turkey under moisture stress in 2016 and 2017 and variable disease infections and genotyped by sequencing in USA. A number of genes were identified for grain yield and its components under drought ${ }^{[32]}$, common bunt resistance $^{[33]}$ and minerals content ${ }^{[34]}$. Several synthetic wheat lines were tested in Azerbaijan and also demonstrated superior yield performance and tolerance to salinity ${ }^{[35]}$.

Training represents a high priority for IWWIP as it improves the capacity of national programs in wheat breeding, research and development. IWWIP conducts a range of training activities. Formal winter wheat breeding training courses are given to a small group of young scientists (3-5 individuals) from CWA every 2 years. The course is for 2-3 months and the trainees are integrated into IWWIP breeding activities with limited formal lectures but with greater emphasis on practical breeding and application of modern tools. Every other year IWWIP conducts the International Winter Wheat Traveling Seminar. It was initiated in 2007 in Turkey to bring together IWWIP breeders and cooperators to share the results, discuss the outcomes, and plan future activities. The traveling seminar was conducted in Ukraine in 2009, Bulgaria and Romania in 2001, Uzbekistan in 2013, Azerbaijan and Georgia in 2015 and Russia in 2017, with the 2019 seminar planned to be in Croatia and Hungary. Normally the seminar attracts 50-60 participants from 20 to 25 countries and has proved to be very successful. In addition, IWWIP conducts short-term training courses devoted to important topics. The latest was conducted in June 2018 on wheat phenotyping methodology and tools and attracted more than 50 participants.

\section{Future perspectives}

The IWWIP has been successful since its formal establishment in 1986 with proven impact in breeding, research and development. The future role of IWWIP depends on its relevance for regional and global wheat production considering the climate change challenges, changing wheat research and breeding framework, increasing pressure of biotic stresses, higher demand for quality and nutritious grain and utilization of environmentally friendly technologies. As long as IWWIP continues to develop and deliver competitive germplasm and services, it will be valued and will have an important place in the global wheat improvement network.

The IWWIP priority traits for breeding are likely to remain the same in the future although some diseases may gain more importance. The future strategy will be based on combining an effective conventional approach with application of new modern tools including precision and high throughput phenotyping, application of genomic tools and molecular markers, speed breeding to accelerate the genetic gains. The Turkey-CIMMYT-ICARDA partnership has proven its viability and efficiency and will continue in the future. All three partners are highly committed to IWWIP. The internal cooperators in Turkey have been participating effectively in all activities and will continue their involvement. The wide range of external partners in CWA, Europe and North America greatly benefit from IWWIP activities and services and will continue their involvement. Overall, IWWIP future perspectives seem encouraging, being based on solid achievements, established framework and flexibility to change and the ability to adapt to new challenges.

Supplementary materials The online version of this articale at 
https://doi.org/10.15302/J-FASE-2019261 contains supplementary material (Table S1).

Acknowledgements IWWIP is supported by the Ministry of Agriculture and Forestry of the Turkish Republic and CRP WHEAT. Contribution of the following individuals to IWWIP success from its establishment is acknowledged: Engin Kınacı, Hasan Ekiz, Nusret Zencirci, Ahmet Bagcı and Yüksel Kaya (from Turkey), Bent Skovemand, Eugene E. Saari, Burt Curtis, Mohamed Mergoum and Arne Hede (from CIMMYT), and Surendra P. S. Beniwal, Habib Ketata, Moussa Mossad, Sanjaya Rajaram and Miguel Sanches-Garcia (from ICARDA).

Compliance with ethics guidelines Alexey Morgounov, Fatih Ozdemir, Mesut Keser, Beyhan Akin, Thomas Payne, and Hans-Joachim Braun declare that they have no conflicts of interest or financial conflicts to disclose.

This article is a review and does not contain any studies with human or animal subjects performed by any of the authors.

\section{References}

1. Rajaram S, van Ginkel M, Fischer R A. CIMMYT's wheat breeding mega-environments (ME). In: Proceedings of the 8th International Wheat Genetic Symposium, Beijing, China. ResearchGate, 1994, 1101-1106

2. Braun H J, Atlin G, Payne T. Multi-location testing as a tool to identify plant response to global climate change. In: Reynolds M ed. Climate Change and Crop Production. CABI, 2010, 115-138

3. Kuhr S R, Johnson V A, Peterson C J, Mattern P J. Trends in winter wheat performance as measured in international trials. Crop Science, 1985, 25(6): 1045-1049

4. Morgounov A, Tufan H A, Sharma R, Akin B, Bagci A, Braun H J, Kaya Y, Keser M, Payne T S, Sonder K, McIntosh R. Global incidence of wheat rusts and powdery mildew during 1969-2010 and durability of resistance of winter wheat variety Bezostaya 1 . European Journal of Plant Pathology, 2012, 132(3): 323-340

5. Akin B, Chen X M, Morgunov A, Zencirci N, Wan A, Wang M. High-temperature adult-plant resistance to stripe rust in facultative winter wheat. Crop \& Pasture Science, 2016, 67(10): 1064-1074

6. Akın B, Yüce S, Singh R, Braun H J, Zencirci N, Morgunov A, Dreisigacker S. Leaf rust (Puccinia triticina) resistance genes determination using race differentials and molecular markers in winter-facultative wheat (Triticum aestivum L.). Agricultural Science Research Journal, 2013, 3(6): 167-177

7. Yu L X, Liu S, Anderson J A, Singh R P, Jin Y, Dubcovsky J, Brown-Guidera G, Bhavani S, Morgounov A, He Z, Huerta-Espino J, Sorrells M E. Haplotype diversity of stem rust resistance loci in uncharacterized wheat lines. Molecular Breeding, 2010, 26(4): 667680

8. Yu L X, Morgounov A, Wanyera R, Keser M, Singh S K, Sorrells M. Identification of Ug99 stem rust resistance loci in winter wheat germplasm using genome-wide association analysis. Theoretical and Applied Genetics, 2012, 125(4): 749-758

9. Morgounov A, Akin B, Demir L, Keser L, Kokhmetova A, Martynov S, Orhan S, Özdemir F, Özseven I, Sapakhova Z, Yessimbekova M. Yield gain due to fungicide application in varieties of winter wheat (Triticum aestivum) resistant and susceptible to leaf rust. Crop \& Pasture Science, 2015, 66(7):
649-659

10. Morgounov A, Haun S, Lang L, Martynov S, Sonder K. Climate change at winter wheat breeding sites in Central Asia, Eastern Europe, and USA, and implications for breeding. Euphytica, 2013, 194(2): 277-292

11. Morgounov A I, Gummadov N, Belen S, Kaya Y, Keser M, Mursalova J. Association of digital photo parameters and NDVI with winter wheat grain yield in variable environments. Turkish Journal of Agriculture and Forestry, 2014, 38: 624-632

12. Gummadov N, Keser M, Akin A, Cakmak M, Mert Z, Taner S, Ozturk I, Topal A, Yazar S, Morgounov A. Genetic gains in wheat in Turkey: winter wheat for irrigated conditions. Crop Journal, 2015, 3 (6): 507-516

13. Keser M, Gummadov N, Akin B, Belen S, Mert Z, Taner S, Topal A, Yazar S, Morgounov A, Sharma R C, Ozdemir F. Genetic gains in wheat in Turkey: winter wheat for dryland conditions. Crop Journal, 2017, 5(6): 533-540

14. Dababat A A, Imren M, Erginbas-Orakci G, Ashrafi S, Yavuzaslanoglu E, Toktay H, Pariyar S R, Elekcioglu I H, Morgounov A I, Mekete T. The importance and management strategies of cereal cyst nematodes, Heterodera spp., in Turkey. Euphytica, 2015, 202(2): 173-188

15. Dababat A A, Erginbas-Orakci G, Toktay H, Imren M, Akin B, Braun H J, Dreisigacker S, Elekcioglu I H, Morgounov A I. Resistance of winter wheat to Heterodera filipjevi in Turkey. Turkish Journal of Agriculture and Forestry, 2014, 38: 180-186

16. Pariyar S R, Dababat A A, Sannemann W, Erginbas-Orakci G, Elashry A, Siddique S, Morgounov A, Leon J, Grundler F M W. Genome-wide association study in wheat identifies resistance to Cereal Cyst Nematode Heterodera filipjevi. Phytopathology, 2016, 106(10): 1128-1138

17. Erginbaş-Orakci G, Morgounov A, Dababat A. Determination of resistance in winter wheat genotypes to the dryland root rots caused by Fusarium culmorum in Turkey. International Journal of Agriculture and Wildlife Science, 2018, 4(2): 193-202

18. Sharma R C, Morgounov A I, Akin B, Bespalova L, Lang L, Litvinenko M, Mustatea P, Ozturk I, Postolatiy A, Rajaram S, Braun H J. Winter wheat eastern European regional yield trial: identification of superior genotypes and characterization of environments. Crop Science, 2014, 54(6): 2469-2480

19. Beil C T, Manmathan H K, Anderson V A, Morgounov A, Haley S D. Population structure and genetic diversity analysis of germplasm from the winter wheat eastern European regional yield trial (WWEERYT). Crop Science, 2017, 57(2): 812-820

20. Beil C T, Anderson V A, Morgounov A, Haley S D. Genomic selection for winter survival ability among a diverse collection of facultative and winter wheat genotypes. Molecular Breeding, 2019, 39(2): 29

21. Mazid A, Keser M, Amegbeto K N, Morgounov A I, Bagci A, Peker K, Akin M, Kucukcongar M, Kan M, Semerci A, Karabak S, Altikat A, Yaktubay S. Measuring the impact of agricultural research: the case of new wheat varieties in Turkey. Experimental Agriculture, 2015, 51(2): 161-178

22. Sharma R C, Rajaram S, Alikulov S, Ziyaev Z, Hazratkulova S, Khodarahami M, Nazeri S M, Belen S, Khalikulov Z, Mosaad M, Kaya Y, Keser M, Eshonova Z, Kokhmetova A, Ahmedov M G, 
Kamali M R. Improved winter wheat genotypes for Central and West Asia. Euphytica, 2013, 190(1): 19-31

23. Tadesse W, Morgounov A I, Braun H J, Akin B, Keser M, Kaya Y, Sharma R C, Rajaram S, Singh M, Baum M, Van Ginkel M. Breeding progress for yield in winter wheat genotypes targeted to irrigated environments of the CWANA region. Euphytica, 2013, 194 (2): 177-185

24. Cakmak I, Yilmaz A, Kalayci M, Ekiz H, Torun B, Ereno B, Braun $\mathrm{H}$ J. Zinc deficiency as a critical problem in wheat production in Central Anatolia. Plant and Soil, 1996, 180(2): 165-172

25. Cakmak I, Kutman U B. Agronomic biofortification of cereals with zinc: a review. European Journal of Soil Science, 2018, 69(1): 172180

26. Kan M, Kucukcongar M, Keser M, Morgounov M, Muminjanov H, Özdemir H, Qualset C. Wheat landraces in farmers' fields in Turkey: national survey, collection and conservation, 2009-2015: Ankara, Turkey. FAO, 2015

27. Morgounov A I, Keser M, Kan M, Küçükçongar M, Özdemir F, Gummadov N, Muminjanov H, Zuev E, Qualset C O. Wheat landraces currently grown in Turkey: distribution, diversity, and use. Crop Science, 2016, 56(6): 3112-3124

28. Sehgal D, Dreisigacker S, Belen S, Küçüközdemir Ü, Mert Z, Özer E, Morgounov A. Mining centuries old in-situ conserved Turkish wheat landraces for grain yield and stripe rust resistance genes. Frontiers in Genetics, 2016, 7: 201

29. Husenov B, Otambekova M, Morgounov A, Muminjanov H. Wheat landraces in farmers' fields in Tajikistan: national survey, collection, and conservation, 2013-2015: Ankara, Turkey. FAO, 2015

30. Baboev S, Morgounov A, Muminjanov H. Wheat landraces in farmers' fields in Uzbekistan: national survey, collection, and conservation, 2010-2015: Ankara, Turkey. FAO, 2015

31. Morgounov A, Abugalieva A, Akan K, Akın B, Baenziger S, Bhatta M, Dababat A A, Demir L, Dutbayev Y, El Bouhssini M, ErginbaşOrakci G, Kishii M, Keser M, Koç E, Kurespek A, Mujeeb-Kazi A, Yorgancilar A, Özdemir F, Özturk I, Payne T, Qadimaliyeva G, Shamanin V, Subasi K, Suleymanova G, Yakişir E, Zelenskiy Y. High-yielding winter synthetic hexaploid wheats resistant to multiple diseases and pests. Plant Genetic Resources, 2018, 16(3): 273-278

32. Bhatta M, Morgounov A, Belamkar V, Baenziger P S. Genomewide association study reveals novel genomic regions for grain yield and yield-related traits in drought-stressed synthetic hexaploid wheat. International Journal of Molecular Sciences, 2018, 19(10): 3011

33. Bhatta M, Morgounov A, Belamkar V, Yorgancilar A, Baenziger P S. Genome-wide association study reveals favorable alleles associated with common bunt resistance in synthetic hexaploid wheat. Euphytica, 2018, 214: 200

34. Bhatta M, Baenziger P S, Waters B M, Poudel R, Belamkar V, Poland J, Morgounov A. Genome-wide association study reveals novel genomic regions associated with 10 grain minerals in synthetic hexaploid wheat. International Journal of Molecular Sciences, 2018, 19(10): 3237

35. Gadimaliyeva G, Aminov N, Jahangirov A, Hamidov $\mathrm{H}$, Abugalieva A, Shamanin V, Morgounov A. Productivity and disease resistance of primary hexaploid synthetic wheat lines and their crosses with bread wheat. Cereal Research Communications, 2018, 46(2): 355-364 